\title{
INTRAANNULAR FUNCTIONALIZATION OF MACROCYCLIC POLYETHERS VIA ORGANOLITHIUM CHEMISTRY;
}

\section{X-RAY STRUCTURE OF 2-SULFINYL-1,3-XYLYL-15-CROWN-4}

Maria Skowronska-Ptasinska, a Pieter Telleman, a Veronika M.L.J. Aarts, a Peter D.J. Grootenhuis, ${ }^{a}$ Johan van Eerden, ${ }^{b}$ Sybolt Harkema, ${ }^{b}$ and David N. Reinhoudt ${ }^{a, *}$

Laboratories of Organic Chemistry ${ }^{a}$ and Chemical Physics, $b$ university of Twente, P.O. Box 217, 7500 AE Enschede, The Netherlands

Abstract - The conversion of 2-1ithio-1,3-xylyl crown ethers (2), obtained by reaction of the 2-bromo-1,3-xylyl crown ethers (1) with n-butyllithium at $-70{ }^{\circ} \mathrm{C}$, with an electrophile is a generally applicable method for the synthesis of 1,3-xylyl crown ethers with intraannular acidic groups.

stable molecular complexes of urea and macrocyclic polyethers seemed to require protonation of urea prior to complexation. ${ }^{l}$ However, recently we have shown that 2-carboxyl-1,3-xylyl crown ethers, providing they can encapsulate urea, are capable of complexing urea via strong hydrogen bonds. ${ }^{2}$ The synthesis of macrocyclic polyethers with covalently linked proton donating groups requires multi-step procedures with low overall yields because of protection of the acidic group during the williamson macrocyclization and subsequent selective deprotection.2,3,4

As part of our work to develop simple procedures for the synthesis of functionalized crown ethers we have recently studied the possibility to take advantage of the presence of ether groups in such macrocycles. However, we found that direct lithiation of crown ethers generally gave ring cleavage. ${ }^{5}$ Hitherto, in our hands direct metalation of simple benzo crown ethers was only succesful under schlosser ${ }^{6}$ conditions (n-butyllithium) potassium tert-butoxide/diethyl ether) at $-80{ }^{\circ} \mathrm{C} .{ }^{7}$ In order to avoid ring cleavage we decided to prepare the organolithium derivatives of $1,3-x y l y 1$ crown ethers via bromine to lithium exchange at temperatures below $-60^{\circ}$. Therefore we have synthesized, according to a modified procedure described by cram et $a 1.8^{8}$ the series of 2-bromo-1,3-xylyl crown ethers $(1 \mathrm{a}-\mathrm{g})$. $0.02 \mathrm{Mol}$ of 2,6-bis(bromomethyl)bromobenzene and $0.02 \mathrm{~mol}$ of a polyethyleneglycol, dissolved in $50 \mathrm{~mL}$ of tetrahydrofuran (THF), were added slowly over a period of 24 hours to a suspension of 3 equivalents of sodium hydride in 2 L of THF at reflux temperature. After extraction of the crude product with hot petroleum ether (40-60) and column chromatography ( $\mathrm{SiO}_{2}$, ethylacetate/ethanol $(9: 1)$ ) the 2-bromo$1,3-x y l y l$ crown ethers $(1 \mathrm{a}-\mathrm{g})$ were isolated in yields sumarized in the Table.

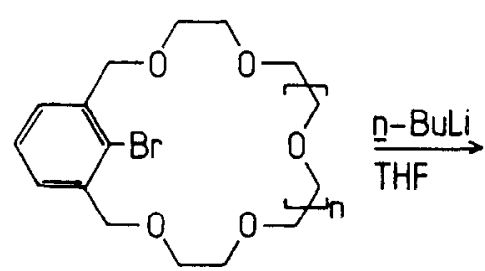

$$
\begin{aligned}
& 1 \mathrm{a}, n=0 \quad \text { e } n=4 \\
& \text { b, } n=1 \quad f \quad n=5 \\
& c n=2 \quad g n=6 \\
& \text { d } n=3
\end{aligned}
$$

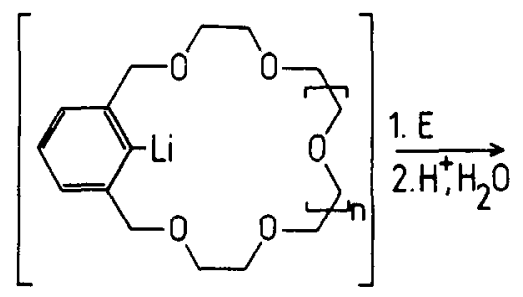

$\underset{\sim}{2}-\underset{\sim}{g}$

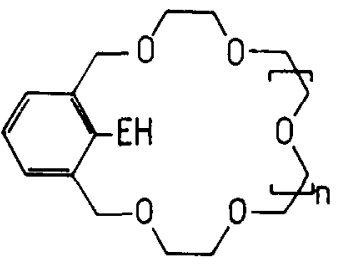

$\underset{\sim}{3} \underset{\sim}{-g}, \mathrm{E}=\mathrm{SO}_{2}$

$4 \mathrm{a}-\mathrm{g}, \mathrm{E}=\mathrm{CO}_{2}$ 
Bromo to lithium exchange was achieved at $-78{ }^{\circ} \mathrm{C}$ by the addition of 2.6 mmol of n-butyllithium (n-BuLi, $1.4 \mathrm{~N}$ in $\underline{n}$-hexane) to a solution of $2.43 \mathrm{mmol}$ of crown ether 1 dissolved in $5 \mathrm{~mL}$ of THF. As soon as the colour of the reaction mixture changed from purple-red to yellow-brown ${ }^{9}$ the organolithium crown ether (2) was reacted with the appropriate electrophile. ${ }^{10}$ The 2 -sulfiny $1-1,3-x y l y 1$ crown ethers (3a-g) were obtained by reacting $2 \mathrm{a}-\mathrm{g}$ with $\mathrm{SO}_{2}$ at $-60{ }^{\circ} \mathrm{C}$ followed by slow warming up to room temperature. Extraction with chloroform, after a small amount of $4 \mathrm{~N} \mathrm{HCl}$ was added to the reaction mixture, gave the crude 2-sulfinyl-1,3-xylyl crown ethers (3a-g). These crown ethers with a strongly acidic intraannular group have never been reported in the literature; they were purified by acid-base extraction, and fully characterized by ${ }_{H} \mathrm{NMR},{ }^{13} \mathrm{C}$ NMR, and (FAB-) mass spectroscopy. Yields are given in the Table.

Table. Yields and Melting Points of the 2-Bromo- (la-g) and 2-Sulfinyl-(3a-g) 1,3-Xylyl Crown Ethers.

\begin{tabular}{|c|c|c|c|c|}
\hline \multirow{2}{*}{ compound } & \multicolumn{2}{|c|}{1} & \multicolumn{2}{|c|}{3} \\
& yield $(8)$ & $\mathrm{mp}\left({ }^{\circ} \mathrm{C}\right)$ & $y$ ield $(8)$ & $\mathrm{mp}\left({ }^{\circ} \mathrm{C}\right)$ \\
\hline a & 41 & $43-47$ & 59 & $102-104$ \\
$\mathrm{~b}$ & 88 & $42-44$ & 67 & $101-104$ \\
$\mathrm{c}$ & 41 & oil & 72 & oil \\
$\mathrm{d}$ & 73 & $55-58$ & 71 & oil \\
$\mathrm{e}$ & 61 & oil & 42 & oil \\
$\mathrm{f}$ & 61 & oil & 70 & oil \\
$\mathrm{g}$ & 60 & oil & 74 & oil \\
\hline
\end{tabular}

Reaction of the 2-1ithio-1,3-xylyl crown ethers with other electrophiles ${ }^{10}$ proved the general applicability of this method for the synthesis of 1,3-xylyl crown ethers with intraannular acidic groups. When $\mathrm{CO}_{2}$ was used as electrophile, 2-carboxyl-1,3-xylyl crown ethers (4) could be obtained by the same procedure as described above for the sulfinyl crown ethers in 60-908 yield. These carboxyl crown ethers were isolated by extraction with dichloromethane, and subsequently purified by acid-base extraction. The 2-carboxyl-1,3-xylyl crown ethers obtained in this way had spectral data in agreement with the data as reported previously.2,3

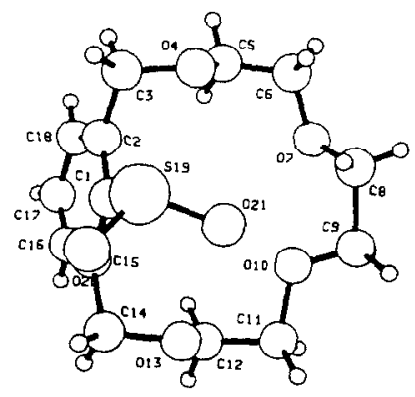

Figure 1. Stereoscopic view of $2-$ sulfiny $1-1,3-x y l y 1-$ 15 -crown-4, (3a) showing atom numbering.

2-Sulfinyl-1,3-xyly 1-15-crown-4 (3a) was obtained as a crystalline compound (mp $\left.101-104^{\circ} \mathrm{C}\right)$, and the structure was established by single crystal $\mathrm{x}$-ray analysis.11 In the solid state $3 a$ adopts the structure with the aromatic ring perpendicular to the mean 
macrocyclic plane. Infortunately the $\mathrm{S}-\mathrm{O}-\mathrm{H}$ hydrogen atom could not be located on 021 $(519-021: 1.54 \AA$ vs $519-020: 1.44 \AA)$. However short distances between this sulfinyl oxygen atom and two crown ether oxygen atoms $(021 \ldots 010: 2.89 \AA$ and $021 \ldots 013: 2.81 \AA$ ) indicate that there most likely is an intramolecular interaction between the sulfinic acid hydrogen and the oxygen atoms of the macrocyclic ring.

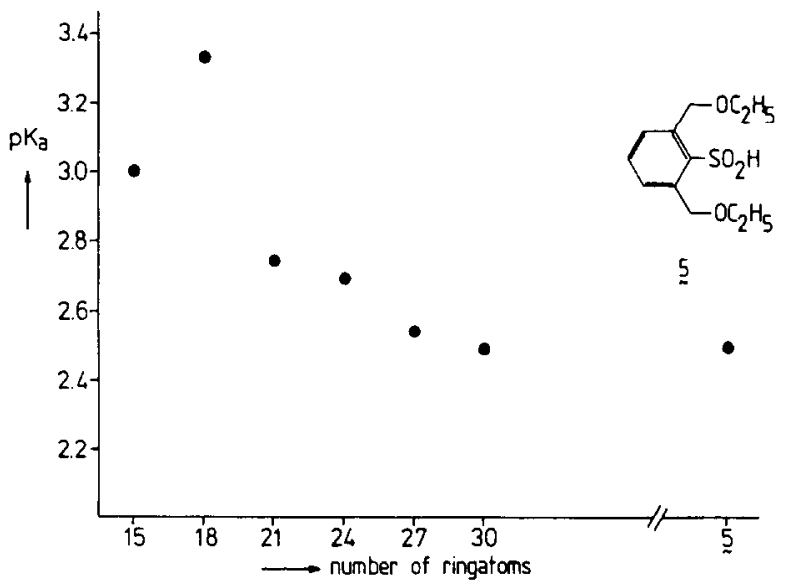

Figure 2. The $\mathrm{pk}$ values of 2 -sulf iny $1-1,3-\mathrm{xy} l y 1$ crown èthers $(3 \mathrm{a}-\mathrm{g})\left(\mathrm{H}_{2} \mathrm{O}, 25.0^{\circ} \mathrm{C}\right)$.

The $\mathrm{pK}_{\mathrm{a}}$ values $\left(\mathrm{H}_{2} \mathrm{O}, 25.0{ }^{\circ} \mathrm{C}\right)$ of the sulfinic acid crown ethers were determined by potentiometric titration ${ }^{15}$ with tetrabutylammonium hydroxide. The $\mathrm{pk}_{\mathrm{a}}$ data depicted in Figure 2 show that the acidities gradually increase with an increasing ring size. The 18-membered macrocycle exhibits a relatively high $\mathrm{pk}_{\mathrm{a}}$ value. Analogous acid-base properties have been observed previously for 2-carboxyl-1,3-xylyl crown ethers (4), 2 although these ligands are less acidic $\left(3.80<\mathrm{pk}_{\mathrm{a}}<5.81\right)$. In the case of the $15-$ and 18 -membered carboxylic crown ethers the enhanced $\mathrm{pk}_{\mathrm{a}}$ values were explained in terms of intraannular hydrogen bonding to crown ether oxygen atoms. ${ }^{2,3} \mathrm{X}$-ray data (vide supra) and CPK model studies indicate a similar explanation is valid for the 15- and 18-membered sulfinic acid crown ethers. For the larger ligands macroring-assisted solvation of the acid may occur. ${ }^{2,16}$ The $\mathrm{pK}_{a}$ values of the 30 -membered ligand and the open-chain mode]. compound 5 are almost equal, showing that stabilization of the sulfinic acid group due to macrocyclic effects is only present for ringsizes < 30 .

Acknowledgement. We would like to thank Professor F. Bickelhaupt (Free University, Amsterdam) for stimulating discussions on intraannular metalation of 1,3-xylyl crown cthers, and Mr. R.H. Fokkens (University of Amsterdam) for measuring the FAB mass spectra of crown ethers 3 .

\section{References and Notes}

(1) (a) S. Harkema, G.J. van Hummel, K. Daasvatn, D.N. Reinhoudt J. Chem. Soc., Chem. Commun. 1981,368 .

(b) V.M.L.J. Aarts, J. Geevers, D.N. Reinhoudt, W. Lengton, M. Bos, J.W.H.M. Uiterwijk, S. Harkema Tetrahedron, accepted for publication.

(c) J.W.H.M. Uiterwijk, S. Harkema, D.N. Reinhoudt, K. Daasvatn, H.J. den Hertog, Jr., J. Geevers Angew. Chem. 1982, 94, 462; Angew. Chem. Suppl. 1982, 1100.

(2) V.M.L.J. Aarts, C.J. van Staveren, P.D.J. Grootenhuis, J. van Eerden, L. Kruise, $\mathbf{S}$. Harkema, D.N. Reinhoudt J. Am. Chem. Soc, 1986, 108, 5035.

(3) M. Newcomb, S.S. Moore, D.J. Cram J. Am. Chem. Soc. 1977, 99, 6405.

(4) (a) C.M. Browne, G. Ferguson, M.A. McKervey, D.L. Mulholland, T. O'Connor, M. Parvez 
J. Am. Chem. Soc. 1985, 107, 2703.

(b) K.E. Koenig, R.C. Helgeson, D.J. Cram J. Am. Chem. Soc. 1976, 98, 4018.

(c) M.A. McKervey, D.L. Mulholland J. Chem. Soc., Chem. Commun. 1977, 438.

(5) Ether cleavage in the presence of organolithium compounds was described previously for dimethoxyethane, J.J. Fitt, H.W. Geschwend J. Org. Chem. 1984, 49, 209, and 2-(methoxyethoxy) benzene, R.A. Ellison, F.N. Kotsonis J. Org. Chem. 1973, 38, 4192.

(6) M. Schlosser J. Organometal. Chem. 1967, 8, 9 .

(7) 3-Lithiobenzo-18-crown-6 could be captured by reaction with dimethyl disulfide in low yield $(\sim 308)$.

(8) Cram et al. ${ }^{3}$ have obtained $1 \mathrm{~b}$ in 78 yield as an oil via the addition of 2,6-bis(bromomethyl)bromobenzene to the disodium salt of tetraethylene glycol in dimethyl formamide at room temperature.

(9) Change of the colour to yellow-brown was observed for the smaller crown ethers (1a-c) almost at once after the addition of n-BuLi, while for crown ethers ld-g this lithiation proces was much slower $(1-3 \mathrm{~h})$.

(10) We found that the reaction with dimethyl disulfide is extremely fast even at low temperature. Therefore we have used this reaction to verify the yield of bromo to lithium exchange. The resulting 2-methylmercapto-1,3-xylyl crown ethers have been characterized by ${ }^{1_{H}}$ NMR, ${ }^{13} \mathrm{C}$ NMR, IR, and mass spectroscopy. Reaction of $2 \mathrm{~d}-\mathrm{g}$ with dimethyl formamide gave the corresponding 2-formyl-1,3-xylyl crown ethers, characterized by ${ }^{l_{H}}$ NMR, IR, and mass spectroscopy.

(11) Crystal data: $C_{14} \mathrm{H}_{20} \mathrm{O}_{6} \mathrm{~S}$, monoclinic, spacegroup $\mathrm{P} 21 / \mathrm{n}, a=9.025(4), b=17.075(6)$, $c=10.277(5) \AA, \quad=105.06(3) \circ, V=1529(2) \AA^{3}, D_{c}=1.37 \mathrm{gcm}^{-3}, z=4, \mu($ MoK $\alpha)=$ $2.2 \mathrm{~cm}^{-1}, \mathrm{~T}=293 \mathrm{~K} .1421$ Reflections measured in the $\omega / 2 \theta$ scan mode up to $\theta=20^{\circ}$. Solution by DIRDIF. ${ }^{12}$ Refinement of 749 observed reflections $\left[\mathrm{F}_{0}{ }^{2}>3 \sigma\left(\mathrm{F}_{0}{ }^{2}\right)\right.$, $\left.\left|F_{0}-F_{C}\right|<9 \sigma\left(F_{O}\right)\right]$. Because of severe disorder, partly due to mediocre crystal quality, the macrocyclic bond distances and angles were restrained and the hydrogens were put in calculated positions and treated as riding on their parent $C$ atoms. The sulfinic acid hydrogen atom could not be located. Final $R=9.68, R_{w}=9.58$ (unit weights) for 121 variables. ${ }^{13}$ All calculations were done using SDP. ${ }^{14}$ To obtain a better accuracy, an $\mathrm{X}$-ray analysis of a crystal of good quality, is to be undertaken.

(12) DIRDIF program (P.T. Beurskens et al., Nijmegen, 1984), incorporated in SDP. 14

(13) Atomic coordinates for this structure have been deposited with the Cambridge Crystallographic Data Centre. The coordinates can be obtained on request from The Director, Cambridge Crystallographic Data Centre, University Chemical Laboratory, Lensfield Road, Cambridge CB2 lEW, U.K..

Complete lists of positional parameters for all atoms and anisotropic thermal parameters for heavy atoms, and 1 ists of bond lengths and bond angles have been deposited as Supplementary Material with the British Library Lending Division, Boston Spa, Wetherby, West Yorks LS23 7BQ, U.K..

(14) Structure Determination Package, B.A. Frenz and Associates Inc., College Station, Texas, and Enraf Nonius, Delft, 1983.

(15) J. Stur, M. Bos, W.E. van der Linden Anal. Chim. Acta 1984, 158, 93.

(16) P.D.J. Grootenhuis, J.W.H.M. Uiterwijk, D.N. Reinhoudt, C.J. van Staveren, E.J.R. Sudhölter, M. Bos, J. van Eerden, W.T. Klooster, L. Kruise, S. Harkema J.Am. Chem. Soc. $1986, \underline{108}, 780$.

(Received in UK 11 February 1987) 